\title{
SAMPLING THE LARVAL STAGES OF THE TWO-YEAR- CYCLE SPRUCE BUDWORM NEAR BABINE LAKE, BRITISH COLUMBIA ${ }^{1}$
}

\author{
By J. W. E. HARRIS ${ }^{2}$
}

\begin{abstract}
Methods of sampling the immature stages of the two-year-cycle spruce budworm, Choristoneura fumiferana (Clem.), were studied at Babine Lake in west-central British Columbia; this paper deals with the larval stages. No significant differences in the numbers of overwintering larvae per square foot of foilage were found between host species or size of sample branch. Significant differences existed between sample trees but a difference between crown levels was found only in the first-year population. No differences were found in the number of feeding larvae between host species, study areas, or crown sides. A difference between sample branch size was found only in the first-year population. Significant differences existed between crown levels, between overstory trees, and between the understory and overstory. An acceptable estimate of larval numbers at least for year-to-year comparison might be obtained by sampling one 18-inch branch tip from the mid-crown portion of as many trees as time permits.
\end{abstract}

\section{INTRODUCTION}

An outbreak of the spruce budworm, Choristoneura fumiferana (Clem.), occurred near Babine Lake in west-central British Columbia from 1954 to 1962. Alpine fir, Abies lasiocarpa (Hook.) Nutt., and white spruce, Picea glauca (Moench) Voss, were the principal tree species attacked. In this area the budworm has a two-year cycle; eggs are laid in even years. The second-instar larvae overwinter in hibernacula and emerge the following spring to feed on buds. They overwinter a second time as fourth-instar larvae and complete their development in the second summer, feeding on older needles as well as on buds.

Studies on sampling the egg stage in this area have been reported (Harris, 1963). In the present paper, studies on sampling the first- and second-year overwintering and the first- and second-year larval stages of the same generation are presented.

Mathers (1932) described the biology of the one-year-cycle form in British Columbia, and he first found the two-year-cycle form. Shepherd (1959) described the two-year-cycle form in the Canadian Rocky Mountains where adults, as in the Babine Lake infestation, were found principally in even

\footnotetext{
${ }^{1}$ Contribution No. 1004, Forest Entomology and Pathology Branch, Department of Forestry, Ottawa, Canada. Based on a thesis submitted to the Faculty of the Graduate School at the State University College of Forestry at Syracuse University, in partial fulfilment of the requirements for the degree of Master of Science, June 1961.

${ }^{2}$ Forest Entomology and Pathology Laboratory, Victoria, B.C.
} 
years. Several workers have studied methods of sampling the one-year-cycle form. Morris (1954, 1955) made an extensive study using as a sample unit a longitudinal one-half branch selected from the mid-crown of trees. Dowden and Carolin (1950) employed a 15-inch and Atwood (1944) an 18-inch branch tip sample. Terrell (1959) studied populations of the overwintering larval stage in the Northern Rocky Mountain Region of the United States.

\section{Methods}

The method of study was similar to that described previously (Harris, 1963). Samples were taken from three areas near Smithers, B.C.

Branches for sampling first- and second-year overwintering larval populations were collected in August, 1958 and 1959, respectively. A southerly facing branch and an 18-inch long cross-section of the bole to which the branch was attached were taken from the middle of each of three crown levels from four white spruce and four alpine fir on Area A. The samples were stored overwinter in the area and transported to Victoria in March. Branches were wrapped in moist paper towelling and suspended over sheets of paper ringed with tanglefoot. Bole sections were placed on paper similarly ringed with tanglefoot. Emerging larvae were counted.

Branches for sampling first- and second-year feeding larval populations were collected in June, 1959 and 1960, respectively. Sample branches with first-year feeding larvae were collected from standing and felled trees with a 20 -foot aluminum extension ladder, pole pruner, and hand clippers. Samples with the more active second-year feeding larval stage were reached with a 40 -foot ladder and were placed immediately in plastic bags for storage until counts could be made. Samples were taken from eight overstory alpine fir and four overstory white spruce on Area $\mathrm{A}$ and from four overstory alpine fir on each of Areas B and C. Eight understory alpine fir were sampled on Area A. From overstory trees, sample branches from the north, southeast, and southwest sides of the bole were taken from the center of each of the upper, middle and lower crown levels, designated $\mathrm{U}, \mathrm{M}$, and $\mathrm{L}$, respectively. Branches were taken from the south side of each understory tree at the mid-crown level. Trees sampled previously for eggs were used in sampling the feeding larvae on the overstory. Successive stages of feeding larvae on the understory and overwintering larvae were each collected from different trees.

Populations were calculated as numbers of larvae per square foot of branch and bole surface. Branches were considered to be roughly triangular and area was determined by multiplying the length by one-half the width. Areas of the bole sections were determined by multiplying the average of the top and butt circumferences by the length.

Comparisons were made by analysis of variance and Student's " $t$ " test. Tests were made on foliage samples to compare differences in numbers of larvae per square foot between sample locations, tree species, overstory trees, overstory and understory trees, crown sides, crown levels, and whole branch and 18-inch tip sample branch sizes. Overwintering larvae were also sampled from bole sections; these were not included in the analyses. 


\section{RESUlTS}

The average numbers of larvae per square foot of foliage are summarized in Table 1. Direct comparison of overwintering larvae with feeding larvae is not possible with these data. The overwintering larvae were divided between foliage and bole while the feeding larvae were confined to the foliage. The proportion overwintering on each is not known. In any case bole and foliage counts could not be combined because the larvae on a particular bole section could have come from any of its branches.

\section{Overwintering Larvae}

Differences between the numbers of first-year overwintering larvae on the two host species, alpine fir and white spruce, were not significant (Table 2). The data were combined to strengthen the analyses. Differences between the individual sample trees were significant. Student's " $t$ " test showed that there were significantly more first-year larvae per square foot of foliage at the upper crown level than at the lower crown level but that there were no significant differences between the numbers at mid-crown and those on the upper or lower crown. There were no significant differences between the numbers of second-year larvae per square foot at the three crown levels. There was no significant difference between the numbers of larvae per square foot on whole branch and 18-inch branch tip samples from the different crown levels for first- or second-year larvae with the exception of the lower crown level for first-year larvae.

There was a greater concentration of larvae overwintering on branches than on 18-inch bole sections. The average numbers of larvae per square foot on foliage and on bole sections were as follows:

\begin{tabular}{lccccr}
\hline \multirow{2}{*}{ Tree species } & \multicolumn{2}{c}{ First-year larvae } & & \multicolumn{2}{c}{ Second-year larvae } \\
\cline { 2 - 3 } \cline { 5 - 6 } & Branches & Bole & & Branches & Bole \\
\hline Alpine fir & 52.3 & 6.7 & 30.2 & 17.9 \\
White spruce & 81.4 & 62.3 & & 8.5 & 9.3 \\
\hline
\end{tabular}

\section{Feeding Larvae}

Differences in the numbers of first- and second-year feeding larvae per square foot of foliage on the two host species and at localities $\mathrm{A}, \mathrm{B}$, and $\mathrm{C}$ were not significant (Table 2). The data were combined to strengthen the analyses. Significant differences were found between sample trees. Student's " $t$ " test showed the mean number of larvae per square foot of foilage on the understory was significantly lower than the mean number on mid-crown overstory samples. No significant differences were found between the numbers of larvae on the three crown sides. Student's " $t$ " test showed that there was a significant difference in the numbers of larvae per square foot between crown levels with the number decreasing from the upper to the lower levels. Significant differences were found between whole branch and 18-inch tip samples of first-year larvae at each crown level but differences in the numbers of second-year larvae were significant only at the lower crown level. 


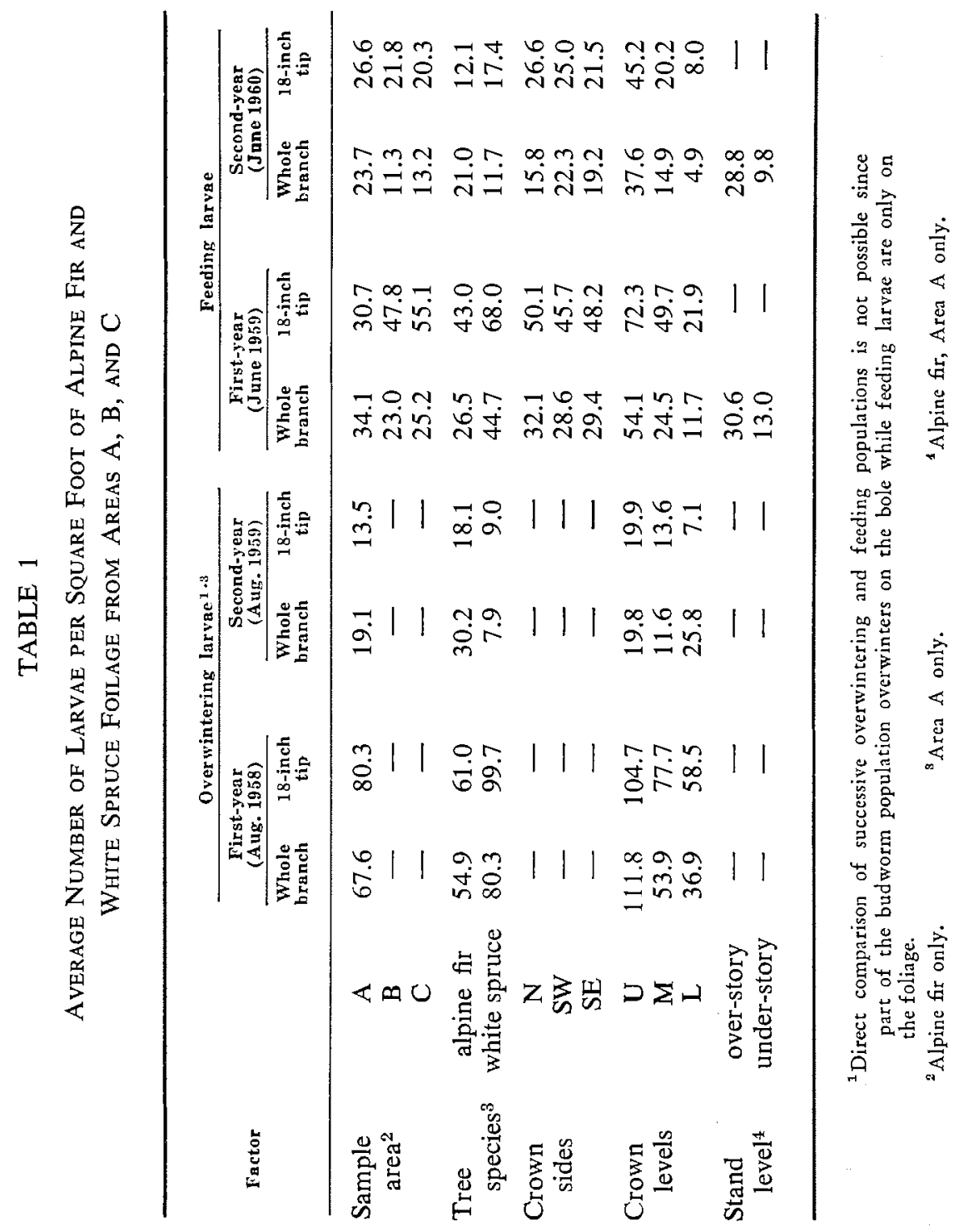


TABLE 2

Significance of Differences in Numbers of LarvaE PER SQUARE Foot of Foliage

\begin{tabular}{|c|c|c|c|c|}
\hline \multirow{2}{*}{ Factor } & \multicolumn{2}{|c|}{ Overwintering larvae } & \multicolumn{2}{|c|}{ Feeding larvae } \\
\hline & First-year & Second-year & First-year & Second-year \\
\hline Sample area & - & 一 & n.s. & n.s. \\
\hline Tree species & n.s. & n.s. & n.s. & n.s. \\
\hline Sample trees & $*$ & $*$ & $*$ & $*$ \\
\hline Crown sides & - & - & n.s. & n.s. \\
\hline Crown levels & * & n.s. & * & $*$ \\
\hline Sample branch size & n.s. ${ }^{1}$ & n.s. & $*$ & n.s. ${ }^{1}$ \\
\hline Understory and overstory & - & 一 & * & n.s. \\
\hline
\end{tabular}

"Differences significant at least at the $5 \%$ level.

n.s. Differences not significant at the $5 \%$ level.

${ }^{1}$ Differences significant at least at the $5 \%$ level except at lower crown level.

- Nor tested.

Number of Larvae per Bud

The number of first-year feeding larvae in each bud averaged 1.2 with a maximum of 13. There were no marked differences in the number of larvae per mined bud at different crown levels. There was never more than one second-year larvae per bud. Most buds in 1960 were completely mined before they began to open and many had been vacated by the larvae before examination.

\section{Discussion}

The results compared closely with those found for the egg stage (Harris, 1963).

The lack of significant differences between host species suggests that at the high population level sampled in this study there was no obvious preference for either host. Samples taken at the peak of outbreaks could presumably be taken from both species indiscriminately but it might be advisable to keep records from the two species separate until further data substantiate this assumption.

The absence of significant differences between feeding larval populations on the three sample areas supports the previous findings that egg populations were fairly uniformly distributed. It also suggests that samples taken in a few areas in a large infestation might give a reasonable estimate of the population. Unpublished Forest Insect Survey records show that the general trend of the outbreak, which covered hundreds of square miles, was obtained by annual samples from less than 20 sample points.

The marked variation between individual trees indicates that a large number of branch samples from each locality would be necessary to reduce the standard error of the mean to 10 per cent of the mean at a probability of 95 per cent. For example, at the population level sampled it would be necessary to increase the number of trees sampled from 20 to 104 when 
sampling first-year feeding larvae, and to 441 when sampling second-year feeding larvae. Differences between overstory samples of feeding larvae were such that only samples from the overstory would be representative of the main stand.

Although estimates of relative year-to-year densities could probably be obtained from any one of the crown levels, the mid-crown is more easily reached than the upper third, and has a higher and probably more stable population than the lower third of the crown. The distribution of feeding larvae appears to be influenced by the availability of foilage buds, which are preferred to older foliage. The tendency is for the greatest number of larvae to congregate high in the crown where the buds are most numerous but when these buds are eaten the larvae spread out over the older foliage. The buds might be defoliated early or late in an infestation, depending on the size of the budworm population.

As there was no real difference in the numbers of feeding larvae on the three crown sides, branch direction could be disregarded. As only one branch from each level was sampled for overwintering larvae, it is not known if the pattern would be the same. However, the results of sampling all other stages point to a similar conclusion for this stage.

As there was no significant difference between means and standard errors of whole branch and 18-inch samples of overwintering and second-year feeding larvae at the mid-crown level, the smaller sample unit could be utilized for these stages. The significant differences between whole branch and 18-inch tip samples found for first-year feeding larvae probably resulted from the preference of these larvae for buds. The buds were concentrated at the tips of banches; more larvae were found there per unit area than over the entire branch. While second-year feeding larvae also appear to prefer buds, most buds had been consumed before sampling was begun and the larvae were spread more evenly over the old foilage. If the population had been lower and more buds had been present, these larvae might also have been concentrated on branch tips and sampling of the tips only might tend to overestimate the population. A satisfactory estimate of total populations of feeding larvae could not be made using 18-inch tip samples but they should be satisfactory for comparing relative population numbers between areas and years. The procedure of Morris (1955), sampling the right or left half of an entire branch, would overcome the problem of bud distribution. The advantages of an 18-inch tip sample are its smaller size and that it avoids the mixing of larvae from the two sides of a branch during sampling before counts are made.

In conclusion, it is suggested that, in general, an adequate relative measure of spruce budworm larval populations can be obtained by sampling an 18-inch branch tip from the mid-portion of the crown of a large number of overstory trees. Whole branch samples would be more reliable for estimating total populations of the feeding stages.

\section{ACKNOWLEDGEMENTS}

The author wishes to thank the following for their assistance with this project: Mrs. P. M. Morse and the late Dr. C. Reimer, Statistical Research 
Service, Canada Department of Agriculture, for advice on statistical methods; Mr. R. R. Lejeune and Dr. G. T. Silver, Forest Entomology and Pathology Laboratory, Victoria, B.C., and Dr. J. Krall, State University College of Forestry at Syracuse University, for aid in planning the project and preparing and editing the manuscript.

\section{REFERENCES}

ATWOOD, C. E. 1944. The feeding habits of young spruce budworm larvae. Can. Ent. 76: $64-66$.

DOWDEN, P. B. and CAROLIN, V. M. 1950. Natural control factors affecting the spruce budworm in the Adirondacks during 1946-1948. J. Econ. Ent. 43: 774-783.

HARRIS, J. W. E. 1963. Sampling the egg stages of the two-year-cycle spruce budworm near Babine Lake, British Columbia. For. Chron. 39: 199-204.

MATHERS, W. G. 1932. The spruce budworm in British Columbia. For. Chron. 8: 154-157.

MORRIS, R. F. 1954. A sequential sampling technique for spruce budworm egg surveys. Can. J. Zool. 32: 302-313.

MORRIS, R. F. 1955. The development of sampling techniques for forest insect defoliators, with particular reference to the spruce budworm. Can. J. Zool. 33: 225-294.

SHEPHERD, R. F, 1959. Phytosociological and environmental characteristics of outbreak and non-outbreak areas of the two-year-cycle spruce budworm, Choristoneura fumiferana. Ecology 40: 608-620.

TERRELL, T. T. 1959. Sampling populations of overwintering spruce budworm in the Northern Rocky Mountain Region. U.S. Dept. Agric., Forest Service, Intermountain Forest and Range Expt. Station. Research Note No. 61. 